\title{
In Scripture: The First Stories of Jewish Sexual Identities, by Lori Hope Lefkovitz
}

Lanham: Rowman \& Littlefield, 20 Io | xii + I90 pages | ISBN: 978-0-7425-4704-9 (hardback) \$49.95

I really delighted in this book. It deals in such clarity with complexity; it reads these ancient biblical texts and finds subtleties that I had never discovered or appreciated before, and opened a new world of meaning.

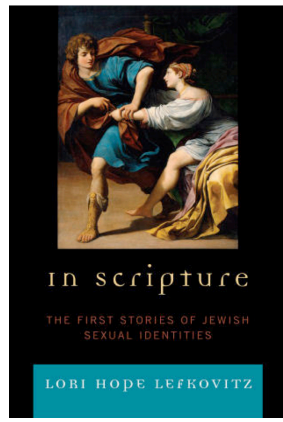
And I had such pleasure in the writing itself. Yet perhaps I should qualify that statement of delight: there were interpretations and readings here that I was not always sure I wanted to accept. Once read, however, I know that I will have to take them into account whenever I read and wrestle with the texts again. As the subtitle indicates the interest lies in the matter of Jewish sexual identity. This is very much a Jewish writer's exploration, frequently referring to "Jewish gender ambiguity," as she traces the roots of contemporary stereotypes of Jewish masculinity, Jewish mothers and the Jewish-American Princess (JAP). Not all lies with the biblical authors; "social Darwinism," for example, is seen as responsible for redefining "man" as "hairy, strong, wild," so that "Isaac, Jacob, Joseph, and ultimately Woody Allen ... become suspect men and 'Jewish man' becomes an oxymoron" (58). At times, as a non-Jew, I felt as if I were eavesdropping upon a conversation that was not mine, although there is acknowledgement that these biblical stories speak to later Christian tradition as well as Jewish, and so many of the insights in these readings and re-readings are universally significant. And I enjoyed the humour: the comment following a discussion of how deception depends upon silences, "Leah and Jacob must have spent a very quiet first night together" (7I).

What is different about this book? Lefkovitz writes that "The purpose that I imagine distinguishes the readings in this book, taken together, is the project of queering or denaturalizing sex in the very place where nature and sex were first and authoritatively invented, represented, and inscribed, at least in this branch of the cultural imagination" (5). Not surprisingly, the book begins with "Eve in the Garden of Signs," for, as she says, "a reading — that is based on a critique of identity-will necessarily discover the beginning of gender trouble in the place where sex begins, in Eden" (I6). The term "gender trouble" is a reminder that for such a project theorists are needed, Judith 
Butler and Sigmund Freud among them. For an underlying position taken throughout the book is that "gender identity and ethnic identity are always performative ... women sometimes act as men, Hebrews double for non-Jews and vice versa ... these narratives highlight the dangerously unstable borders between very old countries: man/woman; Jew/Gentile; God/human" (I 28).

Time and again there is "the confusion of gender categories." For what Lefkovitz reveals is a welter of ambiguity, role confusion, contradiction, border crossings and passings, with binary categories constantly playing against each other. So, for example, "Jacob, under total maternal control, first plays at being a man like Esau.... The competition between Jacob and Esau creates a dynamic by which the patriarch 'is who he is not'.... Conundrums of gender are bound up with the conceptual difficulties of identity more generally" (53). So Jewish sexual identity necessarily brings in the issue of race as well as gender, both a constant thread throughout these early narratives, and also a matter of ambiguity and confusion. Homi Bhabha's work on postcolonial mimicry has ancient roots: "Jacob mimics masculinity and power as his son Joseph and later Moses will also mimic Egyptian nobility. In these Jewish stories, drag and passing are overlapping strategies of miming power that leave a gap within the self, the very space that enables self-deception" (58).

Where is the reception interest? Midrashic readings accompany many of the biblical discussions, the rabbis exhibiting difficulties with some of the biblical attitudes. As Lefkovitz writes, "Midrash rebels against the Bible's untroubled accounts of possible mistreatment of Ishmael and Esau and goes out of its way to vilify the first-born sons in gestures that vindicate the Bible's self-serving patriarchs and their biased mothers" (9I). And why was Joseph so renowned for his beauty and yet so chaste? Was he not really a man? If this bothered the rabbis, later tradition moved further to score masculinity in terms of sexual wildness as a sign of virility. Samuel Richardson's Clarissa and Byron, Heathcliff and Rochester stand as witnesses. It was chapter 4 , however, "Leah behind the Veil: Sex and Sisters from the Bible through Woody Allen" that I found most fascinating in tracing the changes introduced by later writers. Where the rabbis bond the sisters, Rachel and Leah, closer together, Thomas Mann highlights their "natural" sisterly envy. If Jacob and the sisters formed a triangular relationship, real life parallels are to be found in the biographies retelling the lives of Charles Dickens and Sigmund Freud, until finally the complexity of Woody Allen's film, Hannah and Her Sisters, highlighting once again the role of deception and silence in such a relationship. But, Lefkovitz notes, "the real deception is the one that the 
narrative works on the viewers. From Genesis through Hannah and Her Sisters, women are inexplicably, but necessarily, silenced in their relationships to one another" $(84)$. But is this really how it was? And who were the writers, who told these narratives? For, as she declares, there is another story "more rarely developed ... the story beneath this story: Jacob is off-center, not so important; Leah and Rachel love each other and each other's children ... and they do not worry about Jacob nearly as much as he worries about them" (84). Indeed.

As would be expected, the chapter that discusses the "Command Performances of Femininity" in "Bedrooms and Battlefields" includes consideration of art portrayals of Samson and Delilah, and Judith, in particular. Here, in the characters of Jael, Delilah, Esther and Judith, the ancestors of the JAP are found, Lefkovitz noting, however, that "this body of stories ... function as inoculations against desire" (I 27). Stories also come with earlier traditions, with characters refashioned, yet keeping alternative aspects of their former selves alive: so Miriam, water connected in the text, is "a fluid self" (IOO), even perhaps a domesticated sea goddess.

I warmed to the reminder that these early narratives are timeless, that they "open an imaginative mythic space, outside of historical time. A God'seye view is outside of time: as per the Talmudic principle that: 'there is no "late" or "early" in the Torah.' The story that we tell about the deep, dark past depends on who is holding the candle and what she is looking for" (I08). Would that all Bible readers could acknowledge this.

As Lefkovitz sums it up on the last page: "each story is fraught with anxiety and insecurity about identity, expressed through contradiction and category confusion ... all power is tenuous, all love is uncertain." Yet she concludes with reference to the book of Ruth, which both "reiterates and repudiates" the "patterns of representation":

Enemies are beloved; familiar roles are arbitrary; rivalry is absent. All that matters is elemental fertility: bread and babies... Eden re-created in a barley field, we can return to Sinai, where Law is still given and received, without question and with imperfect understanding. Outside of time and space, between once-upon-a time, where stories invent possible worlds, and the peace at the end of time is the narrow bridge of history. It is a dangerous walk of limitless possibility. ( 158 )

If I seem to have quoted more than I have commented, it is out of my respect for the challenges and wisdoms presented in this book. It is provocative in 
the best of senses, leading us, as readers, to revisit old texts and see them as richer and more complex that we had ever understood them. For those of us for whom the Bible or Tanakh is either sacred scripture or cultural icon, this means that we now have to travel with these stories afresh, and let them question our sense of identity and our performative selves. I warmly recommend this book.

Judith E. McKinlay

University of Otago 